\title{
Double Reduction of 4,4'-Bipyridine and Reductive Coupling of Pyridine by Two Thorium(III) Single-Electron Transfers
}

\author{
Alasdair Formanuik, ${ }^{[a]}$ Fabrizio Ortu, ${ }^{[a]}$ Jingjing Liu, ${ }^{[a]}$ Lydia Nodaraki, ${ }^{[a]}$ Floriana Tuna, ${ }^{[a]}$ Andrew \\ Kerridge ${ }^{[b]}$ and David P. Mills*[a]
}

\begin{abstract}
The redox chemistry of uranium is burgeoning and uranium(III) complexes have been shown to promote many interesting synthetic transformations. However, their utility is limited by their reduction potentials, which are smaller than many nontraditional lanthanide(II) complexes. Thorium(III) has a greater redox potential so it should present unprecedented opportunities for actinide reactivity but as with uranium(II) and thorium(II) chemistry these have not yet been fully realized. Here we present reactivity studies of two equivalents of $\left[\mathrm{Th}(\mathrm{Cp})_{3}\right]\left(\mathbf{1}, \mathrm{Cp} "=\left\{\mathrm{C}_{5} \mathrm{H}_{3}\left(\mathrm{SiMe}_{3}\right)_{2}-1,3\right\}\right)$ with 4,4'-bipyridine or two equivalents of pyridine to give $\left[\left\{\mathrm{Th}(\mathrm{Cp} ")_{3}\right\}_{2}\left\{\mu-\left(\mathrm{NC}_{5} \mathrm{H}_{4}\right)_{2}\right\}\right] \quad(2)$ and $\left[\left\{\mathrm{Th}\left(\mathrm{Cp}^{\prime \prime}\right)_{3}\right\}_{2}\left\{\mu-\left(\mathrm{NC}_{5} \mathrm{H}_{5}\right)_{2}\right\}\right] \quad$ (3) respectively, which contain doubly reduced substrates. As relatively large reduction potentials are required to effect these transformations we have shown that thorium(III) can promote reactions that uranium(III) cannot, opening up promising new reductive chemistry for the actinides.
\end{abstract}

Deepening our understanding of the actinides is crucial for the future development of bulk processes associated with nuclear fuel cycles. ${ }^{[1]}$ For example, improved knowledge of reduction potentials developed during the Manhattan project led to the patenting of the PUREX (Plutonium Uranium Redox Extraction) process for selective plutonium extraction. ${ }^{[2]}$ Whilst the reduction potentials of actinides in acidified aqueous solution are well established, ${ }^{[3]}$ these differ markedly for molecular systems and this area is poorly developed for $\mathrm{Th}^{\mathrm{IV}}{ }^{[4]}$ compared to UIII complexes, which have been shown to promote many interesting synthetic transformations. ${ }^{[5]}$ This disparity needs to be addressed as the pace of development of thorium nuclear power continues to intensify. ${ }^{[6]}$ Molecular thorium chemistry is dominated by the +4 oxidation state and there are few examples of structurally characterized Th" ${ }^{[7]}$ and Th"II ${ }^{[7 a, 8]}$ complexes. As with Th"II chemistry, the reactivity of $U^{\prime \prime}$ and $T h^{\prime \prime}$ complexes is currently limited to only a handful of examples. ${ }^{[4,7 a]}$ Standard reduction potential data indicates that Th"I should be far more reducing than $\mathrm{U}^{\mathrm{III}}\left[\mathrm{E}^{\ominus} \mathrm{Th}^{\mathrm{IV}} \rightarrow \mathrm{Th}^{\mathrm{III}}-3.7 \mathrm{~V}\right.$, cf. $\left.\mathrm{U}^{\mathrm{IV}} \rightarrow \mathrm{U}^{\mathrm{III}}-0.6 \mathrm{~V}\right],{ }^{[3]}$ but the enhanced reducing power of a $\mathrm{Th}^{\mathrm{III}}$ complex over a comparable $U^{\text {III }}$ complex in non-aqueous conditions has not been proven experimentally to date. ${ }^{[4,9]}$ Therefore, we envisaged that the treatment of $\left[\mathrm{Th}\left(\mathrm{Cp}^{\prime \prime}\right)_{3}\right]\left(\mathbf{1}, \mathrm{Cp}^{\prime \prime}=\left\{\mathrm{C}_{5} \mathrm{H}_{3}\left(\mathrm{SiMe}_{3}\right)_{2}-1,3\right\}\right)^{[8 \mathrm{e}]}$ with pyridine and 4,4'-bipyridine (4,4'-bipy) would define its reducing capability as the reduction potentials of these $\mathrm{N}$ heterocycles are well-established $\left(E_{1 / 2}\right.$ in $\mathrm{DMF} / 0.1 \mathrm{M} \mathrm{N}^{n} \mathrm{Bu}_{4} \mathrm{I}$ vs. $\mathrm{Ag} / \mathrm{AgCl}$ : py $=-2.76 \mathrm{~V} ; 4,4^{\prime}-$ bipy $=-1.91$ and $\left.-2.47 \mathrm{~V}\right){ }^{[10]}$ and

[a] Dr A. Formanuik, Dr F. Ortu, J. Liu, L. Nodaraki, Dr F. Tuna, Dr D. P. Mills

School of Chemistry, The University of Manchester,

Manchester, M13 9PL (UK)

E-mail: david.mills@manchester.ac.uk

[b] Dr A. Kerridge

Department of Chemistry, Lancaster University,

Lancaster, LA1 4YB (UK) the reduction of these substrates has not previously been mediated by any $U^{\text {III }}$ complex. ${ }^{[5]}$ However, $L n^{\text {II }}$ ( $L n=$ lanthanide) chemistry is now blossoming ${ }^{[11]}$ and the reductive coupling of $\mathrm{N}$ heterocycles by $\mathrm{Ln}^{\|}$( $\mathrm{Ln}=\mathrm{Sm}, \mathrm{Tm}, \mathrm{Yb}$ ) complexes has been studied in depth previously. ${ }^{[12]}$ It is noteworthy that Berthet, Ephritikhine and co-workers have shown that $\mathrm{Ul}_{3}$ can reduce 2,4,6-tris(2-pyridyl)-1,3,5-triazine ${ }^{[13]}$ and $\left[\mathrm{U}\left(\mathrm{Cp}^{\prime}\right)_{3}\right] \quad\left(\mathrm{Cp}^{\prime}\right.$ $\left\{\mathrm{C}_{5} \mathrm{H}_{4} \mathrm{SiMe}_{3}\right\}$ ) can reduce pyrazine. ${ }^{[14]}$ Germane to this study $\mathrm{Th}^{\text {IV }}$ complexes containing direduced 2,2'-bipy have been reported by Walter and $\mathrm{Zi}^{[15-17]}$ and Arnold, ${ }^{[18]}$ and uranium complexes containing mono-reduced 2,2'-bipy have been reported by Bart ${ }^{[19]}$ and Cummins. ${ }^{[20]}$

Two equivalents of $\mathbf{1}$ doubly reduce $4,4^{\prime}$-bipy and reductively couple two equivalents of pyridine to yield $\left[\left\{T h\left(\mathrm{Cp}^{\prime \prime}\right)_{3}\right\}_{2}\{\mu-\right.$ $\left.\left.\left(\mathrm{NC}_{5} \mathrm{H}_{4}\right)_{2}\right\}\right]$ (2) and $\left[\left\{\mathrm{Th}\left(\mathrm{Cp}^{\prime \prime}\right)_{3}\right\}_{2}\left\{\mu-\left(\mathrm{NC}_{5} \mathrm{H}_{5}\right)_{2}\right\}\right]$ (3), respectively (Scheme 1). Although selected $\mathrm{Ln}^{\prime \prime}(\mathrm{Ln}=\mathrm{Sm}, \mathrm{Tm})^{[12 \mathrm{c}-\mathrm{e}]}$ and $\mathrm{Sc}^{\mathrm{III}}$ arene ${ }^{[21]}$ complexes can reductively couple pyridine, Ephritikhine and co-workers have shown by single crystal XRD studies that the comparable $\mathrm{U}^{\prime \prime \prime}$ complexes $\left[\mathrm{U}\left(\mathrm{Cp}^{\prime}\right)_{3}\right]$ and $\left[\mathrm{U}\left(\mathrm{Cp}^{t}\right)_{3}\right]_{(\mathrm{Cp}}{ }^{t}=$ $\left.\left\{\mathrm{C}_{5} \mathrm{H}_{4}{ }_{4} \mathrm{Bu}\right\}\right)$ do not reduce pyridine ${ }^{[14,22]}$ or $4,4^{\prime}$-bipy. ${ }^{[23]}$ The formulations of $\mathbf{2}$ and $\mathbf{3}$ were confirmed by single crystal XRD (Figures $1-2$ ), ${ }^{1} \mathrm{H},{ }^{13} \mathrm{C}\left\{{ }^{1} \mathrm{H}\right\}$ and ${ }^{29} \mathrm{Si}\left\{{ }^{1} \mathrm{H}\right\}$ NMR spectroscopy and elemental analysis (see Supporting Information). The only structurally authenticated thorium complexes containing 4,4'-bipy are $\left[\mathrm{Th}\left(\mathrm{C}_{8} \mathrm{H}_{8}\right)_{2}\left(4,4^{\prime}\right.\right.$-bipy $\left.)\right],{ }^{[24]}\left[\mathrm{Th}\left(\mathrm{OTer}^{\mathrm{Mes}}\right)_{2}\left(\kappa^{3}-\mathrm{BH}_{4}\right)_{2}\left(4,4^{\prime}-\text {-bipy }\right)\right]_{\infty}$ [OTer $\left.{ }^{\text {Mes }} \quad=\quad\left\{\mathrm{C}_{6} \mathrm{H}_{3}\left(\mathrm{C}_{6} \mathrm{H}_{2} \mathrm{Me}_{3}-2,4,6\right)_{2}-2,6\right\}\right] \quad$ and $\left[\mathrm{Th}\left(\mathrm{OTer}{ }^{\mathrm{Mes}}\right)_{2}(\mathrm{Cl})_{2}\left(4,4^{\prime} \text {-bipy }\right)_{1.5}\right]_{\infty},{ }^{[25]}$ which have neutral 4,4'-bipy units. It is noteworthy that $\mathrm{Th}^{\mathrm{IV}}$ complexes containing direduced $2,2^{\prime}$-bipy previously reported in the literature ${ }^{[15-18]}$ have to date exclusively been prepared by reduction of $\mathrm{Th}^{\mathrm{IV}}$ precursors with $\mathrm{KC}_{8}\left(\mathrm{E}_{1 / 2}\right.$ in $\mathrm{DMF} / 0.1 \mathrm{M} \mathrm{N}^{n} \mathrm{Bu}_{4} \mathrm{l}$ vs. $\mathrm{Ag} / \mathrm{AgCl}$ : 2,2'-bipy $=-2.19$ and $-2.76 \mathrm{~V}) .{ }^{[10]}$ Complex 1 does not react with polyaromatics with smaller reduction potentials such as anthracene $\left(E_{1 / 2}=-\right.$ $1.98 \mathrm{~V})$ or naphthalene $\left(\mathrm{E}_{1 / 2}=-2.60 \mathrm{~V}\right),{ }^{[26]}$ indicating that coordination is necessary for electron transfer.

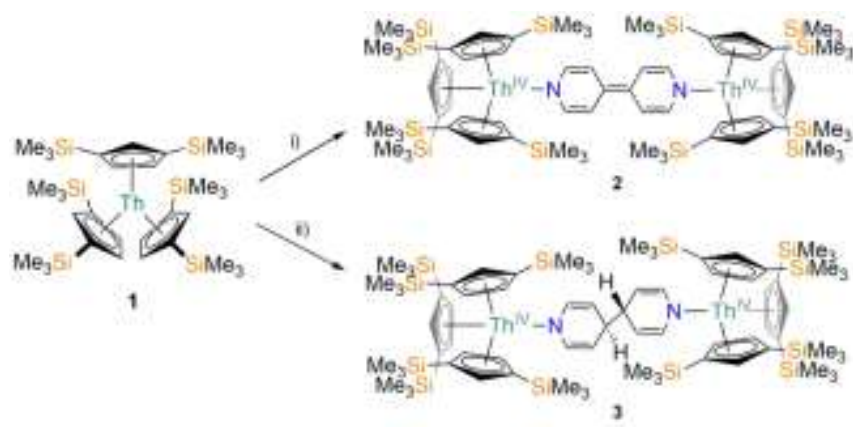

Scheme 1. Synthesis of 2 and 3 from 1: i) 0.5 eq 4,4'-bipy, toluene, 18 h; ii) pyridine, toluene, $5 \mathrm{~d}$. 


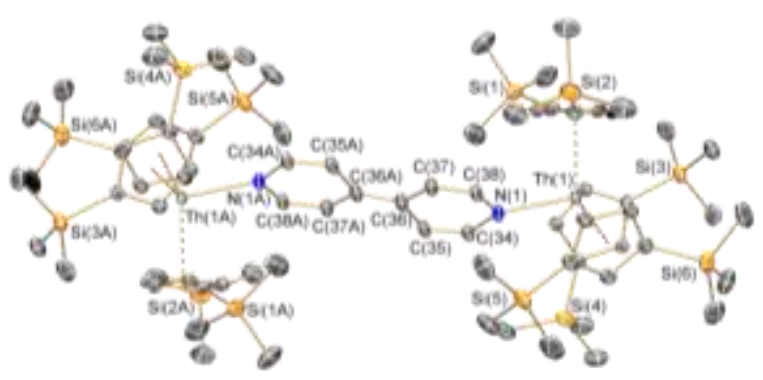

Figure 1. Molecular structure of $\mathbf{2} \cdot \mathbf{C}_{7} \mathrm{H}_{8}$ with selected atom labelling and displacement ellipsoids set to $30 \%$ probability level. Hydrogen atoms and lattice solvent have been omitted for clarity. Selected bond lengths for $2(\AA)$ :

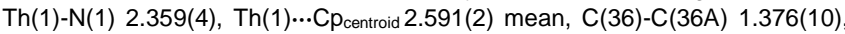

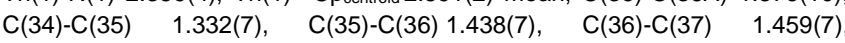
$\mathrm{C}(37)-\mathrm{C}(38) 1.341(7)$



Figure 2. Molecular structure of $\mathbf{3} \cdot \mathbf{C}_{7} \mathrm{H}_{8}$ with selected atom labelling and displacement ellipsoids set to $30 \%$ probability level. Hydrogen atoms [except for those on $\mathrm{C}(36)$ and $\mathrm{C} 36 \mathrm{~A})$ ] and lattice solvent have been omitted for clarity. Selected bond lengths for $3(\AA)$ : $\operatorname{Th}(1)-N(1) 2.350(4), \operatorname{Th}(1) \cdots C p_{\text {centroid }} 2.598(2)$ mean, $\mathrm{C}(36)-\mathrm{C}(36 \mathrm{~A})$ 1.563(11), C(34)-C(35) 1.329(7), C(35)-C(36) 1.497(8), $\mathrm{C}(36)-\mathrm{C}(37)$ 1.502(8), C(37)-C(38) 1.319(8).

The ${ }^{1} \mathrm{H}$ NMR spectrum of 2 is simple and diagnostic of a symmetrical molecule, exhibiting a singlet at $0.45 \mathrm{ppm}$ for the twelve $\mathrm{SiMe}_{3}$ groups, two signals at $7.18 \mathrm{ppm}$ and $6.98 \mathrm{ppm}$ for the $\mathrm{Cp}-\mathrm{H}$ protons and two broad signals at $6.80 \mathrm{ppm}$ and 5.93 $\mathrm{ppm}$ for the two proton environments in the $\left\{\mu-\left(\mathrm{NC}_{5} \mathrm{H}_{4}\right)_{2}\right\}^{2-}$ moiety. In contrast with 2 , the ${ }^{1} \mathrm{H}$ NMR spectrum of 3 in $\left[D_{6}\right]$ benzene is complex as it contains an equilibrium mixture of $\mathbf{3}$, pyridine and a postulated organic radical-bound $\mathrm{Th}^{\mathrm{IV}}$ intermediate complex, "[Th(Cp") $\left.)_{3}(\mathrm{py} \cdot)\right]$ ". Samples of $\mathbf{3}$ in aromatic solvents at room temperature turn pale blue within 30 minutes and intensely blue within 24 hours, indicating the formation of complex $1 .{ }^{[8 \mathrm{c}, \mathrm{e}]}$ Analysis of ${ }^{1} \mathrm{H}$ NMR spectra over several days showed that the relative amount of pyridine in these mixtures also tends to increase over time, so additional experiments were performed to analyse this equilibrium (see below). We found that dissolution of 3 in $\left[D_{6}\right]$ benzene in the presence of a trace amount of pyridine slowed the reverse reaction sufficiently for the NMR spectra to be tentatively assigned. The signals due to 3 in the ${ }^{1} \mathrm{H}$ NMR spectrum of this mixture were assigned as follows: a singlet at $0.48 \mathrm{ppm}$ for the twelve $\mathrm{SiMe}_{3}$ groups, signals at 7.02 and $7.23 \mathrm{ppm}$ for the $\mathrm{Cp}-H$ protons, and signals at $3.89,4.95$ and $6.91 \mathrm{ppm}$ for the protons at the 4-, 3- and 2- positions, respectively of the 4,4'- dihydrobis(4,4'-pyridine)-1,1'-diyl ligand. The ${ }^{13} \mathrm{C}\left\{{ }^{1} \mathrm{H}\right\}$ NMR spectra of 2 and 3 are unremarkable, save for the inter-ring carbons which resonate at 149.56 and $44.13 \mathrm{ppm}$, respectively.
The UV-Visible spectra of 2 and $3(0.1 \mathrm{mM}$ in toluene) were collected between 200-1400 nm (see Supporting Information). Complex 2 exhibits a strong broad absorbance centered at 444 $\mathrm{nm}\left(\varepsilon=19,400 \mathrm{M}^{-1} \mathrm{~cm}^{-1}\right)$, assigned as a $\Pi \rightarrow \pi^{*}$ transition in the conjugated $\pi$-system, which is absent in $\mathbf{3}$. A sample of $3(0.5$ $\mathrm{mM}$ in toluene) was left to stand for four days at ambient temperature to develop an intense blue colour. The UV-vis spectrum of this sample was collected and the absorptions are comparable with an authentic sample of $1 .{ }^{[8 \mathrm{c}]}$

Powder X-band and Q-band EPR spectra of $\mathbf{3}$ were collected at $298 \mathrm{~K}$ (see Supporting Information). These spectra are consistent with an organic radical $(g \approx 2)$, which we tentatively attribute to the presence of "[Th(Cp") $\left.)_{3}(\mathrm{py} \cdot)\right]$ ". No additional features could be modelled when the X-band spectrum was collected at $5 \mathrm{~K}$. In contrast, the frozen solution X-band EPR of 3 in toluene at $40 \mathrm{~K}$ gave a spectrum with axially symmetric $g$ values $\left(g_{z}=1.975 ; g_{x, y}=1.877\right)$ (see Supporting Information). These values correspond well with data previously reported for frozen solution EPR spectra of $\mathbf{1}$ in methylcyclohexane collected from $10-100 \mathrm{~K}\left[g_{z}=1.9725(10) ; g_{x, y}=1.879(1)\right] .{ }^{[8 c]}$

As an equilibrium mixture of compounds forms almost immediately ( $<10 \mathrm{mins})$ when 3 is dissolved in $\left[\mathrm{D}_{8}\right]$ toluene we could not extract kinetic parameters for the reverse reaction by ${ }^{1} \mathrm{H}$ NMR spectroscopy. However, an equilibrium constant, $K_{\mathrm{c}}$, at $298 \mathrm{~K}$ was determined after the solution was left for five days at room temperature to equilibrate by comparing the ${ }^{1} \mathrm{H}$ NMR integrals of pyridine with those attributed to arise from $3\left(K_{\mathrm{c}}=\right.$ $0.5 \mathrm{~mol} \mathrm{dm}^{-3}$ ). The value of this constant did not change when the ${ }^{1} \mathrm{H}$ NMR spectrum was collected at $303 \mathrm{~K}$ or $313 \mathrm{~K}$. In an attempt to show that "[Th(Cp" $\left.)_{3}(\mathrm{py} \cdot)\right]$ " is an intermediate in the formation of 3 a $\left[D_{6}\right]$ benzene solution of 1 containing 2 eq. pyridine was treated with excess 1,4-cyclohexadiene. No benzene or $\mathrm{H}_{2}$ was observed in the ${ }^{1} \mathrm{H}$ NMR spectra of the reaction mixture and after several days crystals of $\mathbf{3}$ formed, so an organic radical intermediate could not be unequivocally proven (see Supporting Information). Finally, no products could be identified from the treatment of 1 with 2 eq. 4-tertbutylpyridine in $\left[D_{6}\right]$ benzene using ${ }^{1} \mathrm{H}$ NMR spectroscopy. This reaction mixture retained the intense blue colour associated with solutions of $\mathbf{1}$, even upon heating to $323 \mathrm{~K}$ for 16 hours (see Supporting Information).

The reversible $\mathrm{C}-\mathrm{C}$ bond formation in $\mathbf{3}$ is analogous to the reactions of the $\mathrm{Fe}^{l}$ complexes $\left[\mathrm{Fe}\left\{[\operatorname{ArNC}(\mathrm{Me})]_{2}\right\}\left(\mathrm{C}_{6} \mathrm{H}_{6}\right)\right](\mathrm{Ar}=$ $\left.\mathrm{C}_{6} \mathrm{H}_{3}{ }^{i} \mathrm{Pr}_{2}-2,6\right)$ or $\left[\left\{\mathrm{Fe}\left[\{\operatorname{ArNC}(\mathrm{Me})\}_{2}\right]\right\}_{2}\left(\mu-\mathrm{N}_{2}\right)\right]$ with pyridine. Both reactions gave an $\mathrm{Fe}^{\| l}$ product containing 4,4'-dihydrobis $(4,4$ 'pyridine)-1,1'-diyl, $\quad\left[\left\{\mathrm{Fe}\left[\{\operatorname{ArNC}(\mathrm{Me})\}_{2}\right]\right\}_{2}\left\{\mu-\left(\mathrm{NC}_{5} \mathrm{H}_{5}\right)_{2}\right\}\right]$, which exhibits a monomer-dimer equilibrium in solution. ${ }^{[27]}$ Pyridine reduction by highly reducing $L \mathrm{Ln}^{\|}$systems is well-established ${ }^{[12]}$ but reversible $\mathrm{C}-\mathrm{C}$ bond formation of an f-element complex containing a reduced unsubstituted pyridine ligand has not previously been observed to the best of our knowledge, although this has been seen for other N-heterocycles. ${ }^{[28]}$ Unsurprisingly, 2 does not react with pyridine to give $\mathbf{3}$ as the reduction potential of $4,4^{\prime}$-bipy is less negative than that of pyridine and 1..$^{[10]}$ In contrast, we found that a $\left[D_{6}\right]$ benzene solution of 3 reacts sluggishly with 4,4'-bipy to give 2 and pyridine. The slow rate of this reaction can be attributed to the equilibrium of $\mathbf{3}$ with $\mathbf{1}$ and 
pyridine, with competitive binding of pyridine and 4,4'-bipy to the single vacant coordination site of $\mathbf{1}$ (see Supporting Information).

A notable feature of the structure of $\mathbf{2}$ is the diagnostic interpyridyl $\mathrm{C}=\mathrm{C}$ double bond length $[1.376(10) \AA]$, which is significantly shorter than those seen in 4,4'-bipy adducts such as $\left[\left\{\mathrm{U}\left(\mathrm{Cp}^{\prime}\right)_{3}\right\}_{2}\left(4,4^{\prime}\right.\right.$-bipy $\left.)\right][1.474(17) \AA]^{[23]}$ or $\left[\mathrm{Th}\left(\mathrm{C}_{8} \mathrm{H}_{8}\right)_{2}\left(4,4^{\prime}-\right.\right.$-bipy $\left.)\right]$ $[1.478(4) \AA]^{[24]}$ and is comparable to the distances in other direduced 4,4'-dihydrobis(4,4'-pyridine)-1,1'-diyl complexes ${ }^{[29]}$ and bis(trimethylsilyl)dihydro-4,4'-bipy [C=C: 1.381 (3) Å]. ${ }^{[29 a]}$ The intra-pyridyl bond lengths are also diagnostic of direduction. The inter-ring $\mathrm{C}-\mathrm{C}$ distance in 3 [1.562(12) $\AA$ ] is typical of a single bond and this, together with other heterocyclic ring metrics, is comparable with similar complexes in the literature..$^{[12 c-e, 21,27]}$ The Th-N distances in 2 [2.359(4) $\AA$ ] and 3 [2.350(4) $\AA$ ] are shorter than those in $\mathrm{Th}^{\mathrm{IV}}$ 4,4'-bipy adducts [range: 2.626(2)-2.707(2) $\AA]^{[24,25]}$ and are typical of $\mathrm{Th}^{\mathrm{IV}}-\mathrm{N}$ amide bonds, e.g. $\left[\mathrm{Th}\left\{\mathrm{N}\left(\mathrm{SiMe}_{3}\right)_{2}\right\}_{3}\left(\mathrm{BH}_{4}\right)\right]\left[2.32(2) \AA ̊ \AA .{ }^{[30]}\right.$

The electronic structures of $\mathbf{2}$ and $\mathbf{3}$ were characterized at the density functional theory (DFT) level, employing the PBE0 exchange-correlation functional and a polarized split-valence basis set for structural optimizations (see Supporting Information for full details). Electronic properties were derived from singlepoint energy calculations using a polarized valence triple- $\zeta$ basis set. Structural parameters were in excellent agreement with experiment, with bond lengths typically deviating from experimental values by less than $0.02 \AA$ (see Supporting Information Table S4), justifying the model chemistry. Further confidence in these models was provided by the bulk features of the UV/visible spectrum of $\mathbf{2}$ and the IR spectra of $\mathbf{2}$ and $\mathbf{3}$ being reproduced with reasonable agreement by calculated values (see Supporting Information Tables S5-7). Inspection of the resultant molecular orbitals reveals the presence of both $\sigma$ - and $\pi$-type Th-N bonding interactions (Figure 3), although the thorium contributions are, as would be expected, small.

The Th-N bond orders, obtained via the quantum theory of atoms in molecules (QTAIM)/Mayer approaches, were calculated to be $0.558 / 0.767$ and $0.573 / 0.798$ for 2 and 3, respectively. NBO analysis failed to identify any Th-N bonding orbitals, presumably due to Th contributions falling below the $5 \%$ default threshold, but Th contributions to the orbitals shown in Figure 3 were estimated via QTAIM and Hirshfeld partitioning of the molecular spaces. Both methods predicted small ( 2-4\%) Th contributions, and $\mathbf{3}$ was further investigated using QTAIM (See


$\pi$

3
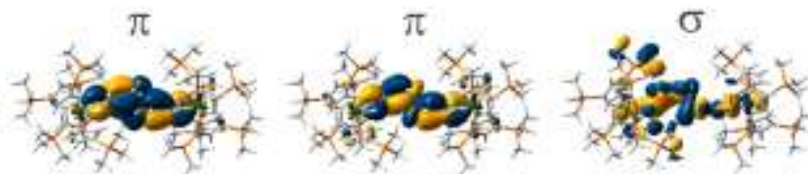

Figure 3. Selected MOs of 2 and 3, exhibiting either Th-N $\pi$ - or $\sigma$-bonding character. All MOs rendered using an isosurface value of 0.015 a.u.
Supporting Information Table S9). All metrics indicate a predominantly ionic $\mathrm{Th}-\mathrm{N}$ interaction with very similar covalent character. QTAIM metrics suggest a slightly more covalent interaction in 3. This is commensurate with the higher bond order and shorter Th- $\mathrm{N}$ bond: combined these measures indicate a stronger Th-N bond in 3 . Th- $\mathrm{N}$ bond ellipticities were calculated to be 0.29 and 0.27 for 2 and 3 , respectively. When compared to those of benzene $(0.23)$ and ethylene $(0.45)$ these values indicate a degree of double bond character in the $\mathrm{Th}-\mathrm{N}$ bonds of 2 and $\mathbf{3}$.

To conclude, we have demonstrated that two equivalents of the Th"II complex 1 promote the double reduction of 4,4'bipyridine and the reductive coupling of pyridine. This work shows that Th"II complexes can exhibit reductive chemistry of the order of non-traditional L $\mathrm{Ln}^{\text {" }}$ systems, opening up new reductive chemistry for the actinides. The consequence is that the reductive small molecule activation chemistry of $\mathrm{Th}^{\mathrm{III}}$, thus far burgeoning only for $U^{\prime \prime \prime}$ in the actinide series, should yield contrasting and fascinating results in future.

\section{Experimental Section}

Full synthetic details, characterization data and computational data for 2-3 is available in the Supporting Information. Additional research data supporting this publication are available from The University of Manchester eScholar repository at DOI:10.15127/1.302738.

\section{Acknowledgements}

We acknowledge the Engineering and Physical Sciences Research Council (grant numbers EP/K039547/1, EP/L014416/1 and EP/J002208/2), the Nuclear FiRST DTC, the EPSRC UK National Electron Paramagnetic Resonance Service and the University of Manchester for supporting this work.

Keywords: thorium $\cdot \mathrm{N}$ ligand $•$ subvalent compounds • reduction $\cdot$ electron transfer

[1] The Chemistry of the Actinide and Transactinide Elements, 3rd ed (Eds.: L. R. Morss, N. M. Edelstein, J. Fuger, J. J. Katz), Springer, Dordrecht, 2006.

[2] H. H. Anderson, L. B. Asprey, 1947, US patent 2924506

[3] E L. J. Nugent, R. D. Baybarz, J. L. Burnett, J. L. Ryan, J. Phys. Chem 1973, 77, 1528-1539.

[4] F. Ortu, A. Formanuik, J. R. Innes, D. P. Mills, Dalton Trans. 2016, 45, 7537-7549

[5] S. T. Liddle, Angew. Chem. Int. Ed. 2015, 54, 8604-8641.

[6] a) D. Heuer, E. Merle-Lucotte, M. Allibert, M. Brovchenko, V. Ghetta, P. Rubiolo, Ann. Nucl. Energy 2014, 64, 421-429; b) P. Bagla, Science 2015, 350, 726-727.

[7] a) R. R. Langeslay, M. E. Feiser, J. W. Ziller, F. Furche, W. J. Evans, J. Am. Chem. Soc. 2016, 138, 4036-4045; b) R. R. Langeslay, M. E. Feiser, J. W. Ziller, F. Furche, W. J. Evans, Chem. Sci. 2015, 6, 517521.

[8] a) N. A. Siladke, C. L. Webster, J. R. Walensky, M. K. Takase, J. W. Ziller, D. J. Grant, L. Gagliardi, W. J. Evans, Organometallics 2013, 32, 6522-6531; b) J. R. Walensky, R. L. Martin, J. W. Ziller, W. J. Evans, 
Inorg. Chem. 2010, 49, 10007-10012; c) P. C. Blake, N. M. Edelstein P. B. Hitchcock, W. K. Kot, M. F. Lappert, G. V. Shalimoff, S. Tian, J Organomet. Chem. 2001, 636, 124-129; d) J. S. Parry, F. G. N. Cloke S. J. Coles, M. B. Hursthouse, J. Am. Chem. Soc. 1999, 121, 68676871; e) P. C. Blake, M. F. Lappert, J. L. Atwood, H. Zhang, J. Chem. Soc., Chem. Commun. 1986, 1148-1149.

[9] a) A. Formanuik, F. Ortu, R. Beekmeyer, A. Kerridge, R. A. Adams, D. P. Mills, Dalton Trans. 2016, 45, 2390-2393; b) A. Formanuik, F. Ortu, C. J. Inman, A. Kerridge, L. Castro, L. Maron, D. P. Mills, Chem. Eur. J., 2016, 22, 17976-17979.

[10] B. J. Tabner, J. R. Yandle, J. Chem. Soc. A 1968, 381-388.

[11] For reviews see, for example: a) W. J. Evans, Organometallics 2016 , 35, 3088-3100; b) F. Nief, Dalton Trans. 2010, 39, 6589-6598; c) W. J. Evans, J. Alloys Compd. 2009, 488, 493-510; d) W. J. Evans, Inorg. Chem. 2007, 46, 3435-3449; e) M. K. Bochkarev, Coord. Chem. Rev. 2004, 248, 835-851; f) W. J. Evans, Coord. Chem. Rev. 2000, 206-207, 263-283.

[12] a) C. E. Kefalidis, S. Essafi, L. Perrin, L. Maron, Inorg. Chem. 2014, 53 , 3427-3433; b) W. Ren, H. Song, G. Zi, M. D. Walter, Dalton Trans. 2012, 41, 5965-5973; c) S. Labouille, F. Nief, X. Le Goff, L. Maron, D. Kindra, H. L. Houghton, J. W. Ziller, W. J. Evans, Organometallics 2012, 31, 5196-5203; d) F. Jaroschik, F. Nief, X. -F. Le Goff, L. Ricard, Organometallics 2007, 26, 3552-3558; e) I. L. Fedushkin, V. I. Nevodchikov, M. N. Bochkarev, S. Dechert, H. Schumann, Russ. Chem. Bull. 2003, 52, 154-159.

[13] J.-C. Berthet, P. Thuéry, C. Baudin, B. Boizot, M. Ephritikhine, Dalton Trans. 2009, 7613-7616.

[14] T. Mehdoui, J.-C. Berthet, P. Thuéry, M. Ephritikhine, Eur. J. Inorg. Chem. 2004, 1996-2000.

[15] a) W. Ren, W. W. Lukens, G. Zi, L. Maron, M. D. Walter, Chem. Sci. 2013, 4, 1168-1174; b) W. Ren, G. Zi, M. D. Walter, Organometallics 2012, 31, 672-679.

[16] W. Ren, H. Song, G. Zi, M. D. Walter, Dalton Trans. 2012, 41, 59655973.

[17] P. Yang, E. Zhou, B. Fang, G. Hou, G. Zi, M. Walter, Organometallics, 2016, 35, 2129-2139.
[18] a) M. E. Garner, S. Hohloch, L. Maron, J. Arnold, Angew. Chem, Int, Ed. 2016, 55, 13789-13792; b) M. E. Garner, S. Hohloch, L. Maron, J. Arnold, Organometallics 2016, 35, 2915.

[19] S. J. Kraft, P. E. Fanwick, S. C. Bart, Inorg. Chem. 2010, 49, 11031110.

[20] P. L. Diaconescu, C. C. Cummins, Dalton Trans. 2015, 44, 2676-2683.

[21] W. Huang, S. I. Khan, P. L. Diaconescu, J. Am. Chem. Soc. 2011, 133, 10410-10413.

[22] T. Mehdoui, J.-C. Berthet, P. Thuéry, M. Ephritikhine, Dalton Trans. 2004, 579-590.

[23] T. Mehdoui, J.-C. Berthet, P. Thuéry, M. Ephritikhine, Private Communication to the CSD, 2013, CCDC 958634

[24] J.-C. Berthet, P. Thuéry, N. Garin, J.-P. Dognon, T. Cantat, M Ephritikhine, J. Am. Chem. Soc. 2013, 135, 10003-10006.

[25] J. McKinven, G. S. Nichol, P. L. Arnold, Dalton. Trans. 2014, 43 17416-17421.

[26] W. J. Evans, S. L. Gonzales, J. W. Ziller, J. Am. Chem. Soc. 1994, 116, 2600-2608

[27] T. R. Dugan, E. Bill, K. C. MacLeod, G. J. Christian, R. E. Cowley, W. W. Brennessel, S. Ye, F. Neese, P. L. Holland, J. Am. Chem. Soc. 2012, 134, 20352-20364.

[28] a) W. J. Evans, D. K. Drummond, J. Am. Chem. Soc. 1989, 111, 3329 3335; b) D. J. Berg, J. M. Boncella, R. A. Andersen, Organometallics 2002, 21, 4622-4631; c) G. Nocton, W. W. Lukens, C. H. Booth, S. S. Rozenel, S. A. Medling, L. Maron, R. A. Andersen, J. Am. Chem. Soc. 2014, 136, 8626-8641; d) G. Nocton, C. H. Booth, L. Maron, L. Ricard R. A. Andersen, Organometallics 2014, 33, 6819-6829; e) G. Nocton, L. Ricard, Dalton Trans. 2014, 43, 4380-4387; f) G. Nocton, L. Ricard, Chem. Commun. 2015, 51, 3578-3581.

[29] a) S. Kraft, E. Hanuschek, R. Beckhaus, D. Haase W. Saak, Chem. Eur J. 2004, 11, 969-978; b) M. Irwin, T. Kramer, J. E. McGrady, J. M Goicoechea, J. M. Inorg. Chem. 2011, 50, 5006-5014, and references cited therein.

[30] H. W. Turner, R. A. Andersen, A. Zalkin, D. H. Templeton, Inorg. Chem 1979, 18, 1221-1224 


\section{Entry for the Table of Contents}

COMMUNICATION

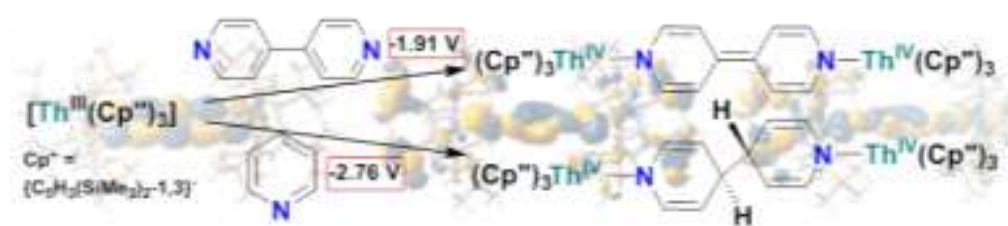

The Mighty Thorium: The reductive chemistry of the thorium(III) complex, $\left[\mathrm{Th}\left\{\mathrm{C}_{5} \mathrm{H}_{3}\left(\mathrm{SiMe}_{3}\right)_{2}-1,3\right\}_{3}\right]$, is shown to be of the order of non-traditional lanthanide(II) complexes, opening up new reductive chemistry for the actinides.
Alasdair Formanuik, Fabrizio Ortu,

Floriana Tuna, Andrew Kerridge, and David P. Mills*

Page No. - Page No.

Double Reduction of 4,4'-Bipyridine and Reductive Coupling of Pyridine by Two Thorium(III) Single-Electron Transfers 